\title{
LAS LEYES DE EDUCACIÓN EN LOS COMIENZOS DEL SIGLO XXI: DEL NEOLIBERALISMO AL POSTCONSENSO DE WASHINGTON EN AMÉRICA DEL SUR
}

\author{
FERNANDA SAFORCADA* \\ AlejANDRO VASSILIADES**
}

\begin{abstract}
RESUMEN: América Latina se caracteriza, en la actualidad, por la diversidad de los procesos políticos en marcha en un contexto de crisis hegemónica del neoliberalismo. Como parte de estos procesos políticos, desde 2003 en adelante se han sancionado nuevas leyes generales de educación en numerosos países. El presente trabajo analiza las leyes de educación vigentes en los países suramericanos a partir de algunos tópicos fundamentales de la política educacional: cuáles son los fines de la educación, qué rol asume el Estado, cómo se define el derecho a la educación y cuáles son las dimensiones consideradas en relación con su consecución, entre otras. El estudio de las leyes desde una perspectiva comparada permite observar un panorama diverso y complejo que resulta significativo para comprender las orientaciones y los debates actuales en materia educativa para esta parte del continente.
\end{abstract}

Palabras clave: Política educativa. Ley de educación. Latinoamérica. Estado. Derecho a la educación.

\section{EDUCATION LAWS IN THE EARLY $21^{\text {st }}$ CENTURY: FROM NEOLIBERALISM TO THE POST-WASHINGTON CONSENSUS in SOUth AMERica}

\begin{abstract}
Latin America is currently experiencing an ongoing diversity of political processes in a context of crisis of the neoliberalism hegemony. In this context, new general education laws have been sanctioned in many countries, from 2003 onwards. Considering some fundamental topics of education policies, this paper analyses the education laws in force in South American countries such as, among others: What are the aims of education? What is the role of the State? How is the right to education defined? And, which aspects are considered to implement it? Studying these topics from a comparative point of view reveals a rich and complex overlook that help us understand the present orientations and debates in educational matters for this part of the continent.
\end{abstract}

Key words: Educational politics. Education law. Latin America. State. Right to education.

\footnotetext{
* $\quad$ Magister en Ciencias Sociales y docente de la Universidad de Buenos Aires (UBA). E-mail: fsaforcada@gmail.com

** Maestre en Ciencias Sociales y docente de la Universidad de Buenos Aires y de la Universidad Nacional de La Plata. E-mail: alevassiliades@gmail.com
} 
LES LOIS SUR L'ÉDUCATION AU DÉBUT DU XXI ${ }^{\mathrm{E}}$ SIÈCLE: DU NÉOLIBÉRALISME À L'APRÈs CONSENSUS de WASHINGTON EN AMÉRIQUe du Sud

RÉSUMÉ: De nos jours, l'Amérique Latine se caractérise par la diversité des processus politiques en cours dans un contexte de crise hégémonique du néolibéralisme. Dans ce cadre, depuis 2003, des lois générales d'éducation ont été promulguées dans de nombreux pays. Ce travail analyse les lois sur l'éducation en vigueur dans les pays sud-américains à partir de certains thèmes fondamentaux de la politique éducationnelle, comme, entre autres : les fins de l'éducation; le rôle assumé par l'État; la définition du droit à l'éducation; et les dimensions considérées pour la mettre en œuvre. L'étude des lois à partir d'un point de vue comparatif offre une vue d'ensemble diverse et complexe et, donc, importante pour comprendre les orientations et les débats actuels en matière d'éducation dans cette partie du continent.

Mots-clés: Politique éducative. Loi sur l'éducation. Amérique Latine. État. Droit a l'éducation.

\section{Introducción}

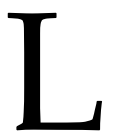

atinoamérica es, sin dudas, una región dinámica, que ha vivido numerosos cambios políticos y sociales en los últimos años y que presenta hoy un panorama muy diverso. Luego de las dictaduras y los gobiernos de Nueva Derecha de las últimas décadas, América del Sur se caracteriza en la actualidad por estar llevando adelante procesos políticos muy dispares e incluso antagónicos, con regímenes claramente neoliberales en algunos países, procesos intensos de transformación en otros, y, en otros más, gobiernos que, sin llevar adelante cambios radicales, buscan recomponer lo social con el desarrollo de políticas más inclusivas y un fuerte giro en el rol que asume el Estado.

La educación, como no podría ser de otro modo, acompañó y acompaña estos procesos. En los años 90, fue una de las dimensiones de las reformas del Estado que se impulsaron en la región. Entre los componentes de estas reformas educativas, uno de los de mayor gravitación simbólica fue la sanción de leyes generales de educación que encarnaban las orientaciones dominantes. El énfasis en la calidad de la educación, el protagonismo del sector privado y de los particulares, la autonomía de la escuela y los agentes, la evaluación y la rendición de cuentas, la competencia y la eficiencia conformaron el núcleo de las políticas educativas de modernización neoliberal y de las leyes que las acompañaron (Feldfeber, 2000; Tiramonti, 2001; Krawczyk y Vieira, 2008).

En los años que corren, el escenario educativo es notoriamente menos homogéneo. Las mismas diversidades y contradicciones que estamos viviendo en Latinoamérica, en los procesos sociopolíticos amplios, pueden observarse en las orientaciones de las políticas educativas en marcha en los distintos países sudamericanos y 
en sus legislaciones educativas, como veremos en el presente trabajo. A la fecha, de los diez países latinoamericanos del sur del continente, siete han sancionado nuevas leyes luego del año 2000. Los tres restantes aún mantienen las acuñadas en la década del 90.

Este artículo analiza, desde una perspectiva comparada, las leyes generales de educación vigentes en los países latinoamericanos del sur, en función de los siguientes ejes: los fines que orientan la educación, el rol que asume el Estado, las definiciones en torno a lo público y lo privado, y la concepción de derecho a la educación. Asimismo, estudia qué continuidades presentan las nuevas normas sancionadas respecto de las políticas hegemónicas durante los 90 y cuáles son las rupturas más significativas.

Las leyes analizadas fueron las siguientes: Ley de la Educación "Avelino Siñani - Elizardo Pérez" n. 070, Bolivia, 2010; Ley General de Educación n. 20.370, Chile, 2009; Ley General de Educación n. 18.437, Uruguay, 2009; Ley Orgánica de Educación, Venezuela, 2009; Ley de Educación Nacional n. 26.206, Argentina, 2006; Ley General de Educación n. 28044, Perú, 2003; Ley General de Educación n. 1.264, Paraguay, 1998; Lei de Diretrizes e Bases da Educação Nacional n. 9.394, Brasil, 1996; y Ley General de Educación n. 115, Colombia, 1994. ${ }^{1}$ La Ley Orgánica de Educación Intercultural de Ecuador no fue considerada debido a que fue aprobada recientemente, luego de un arduo proceso de debate, y el texto definitivo aún no se estaba disponible al momento de finalización de este artículo.

Las leyes en conjunto conforman un material particularmente rico, que denota las características actuales de la región, los procesos políticos diversos en cada país y los esfuerzos de algunos por la construcción de modelos alternativos, pero que también refleja "de dónde venimos", hasta qué punto el neoliberalismo construyó hegemonía en términos de ciertos modos de pensar la educación que hoy continúan vigentes.

Antes de introducirnos en el análisis, es necesario realizar dos aclaraciones, vinculadas con el recorte de este artículo y los alcances de la indagación llevada a cabo. En primer término, el análisis que se presenta no tuvo en consideración, salvo en algunas cuestiones generales, el devenir histórico de los sistemas educativos en cada uno de los países ni la coyuntura de sanción de cada ley. En segundo lugar, no hemos considerado otras leyes - como los decretos reglamentarios, las leyes de educación superior o los reglamentos de carrera magisterial - íntimamente vinculadas con las leyes generales. Cada norma debería ser leída a la luz de los procesos sociales históricos del país, inscripta en el contexto en el que fue aprobada y en vínculo con otras legislaciones. No obstante, este tipo de análisis excedía largamente las posibilidades del presente trabajo. 
A pesar de esas limitaciones, creemos que construir una mirada comparada que permita sistematizar lo que establecen, regulan y norman las leyes generales de educación en los países suramericanos constituye un aporte para comenzar a tejer algunas claves de comprensión respecto de la realidad latinoamericana actual en materia de política educativa.

\section{Las leyes de educación vigentes: algunos ejes de análisis}

Las leyes de educación presentan una gran diversidad en sus contenidos y en los tópicos que recorren en su articulado. Para poder desarrollar una mirada comparada, definimos cuatro ejes de análisis, entre muchos otros posibles, que abordan algunos de los principales temas y debates del campo de la política educacional.

\section{Acerca de los fines y las orientaciones de la educación}

Toda ley educativa suele contener definiciones acerca de qué sentidos y expectativas se asocian a la educación. Estas definiciones son un aspecto central en el análisis político-educativo tanto porque enmarcan una serie de enunciaciones y decisiones políticas respecto de qué hacer con la educación, como porque permiten analizar cómo se expresan en la legislación las orientaciones de política educativa adoptadas por los países de la región.

En las leyes vigentes en Suramérica, las afirmaciones relativas a las concepciones y fines de la educación incorporan planteos tradicionales a la vez que introducen nuevos matices vinculados a la situación política actual de esta parte del continente. Entre las definiciones aparecen referencias a procesos que tienen por objetivo la formación para la ciudadanía y para el trabajo, recuperando formas históricas de definir las expectativas sobre la escolarización en la región. Estos fines, a su vez, se articulan con el desarrollo del país, como sucede en las leyes de Argentina, Chile y Uruguay, incorporando una asociación entre educación y desarrollo (económico, social o desarrollo "sostenible") que reedita la concepción de progreso propia del contexto desarrollista de las décadas del 60 y 70, y se distancia de las reformulaciones de este par hechas en la década del 90 desde racionalidades neoliberales que ponían el foco en el mercado y la competitividad (Feldfeber, 1997).

Entre los fines, un rasgo medular que comparte la mayoría de las leyes analizadas es la referencia al desarrollo integral de la persona humana o del educando (Colombia, Argentina, Chile, Brasil, Uruguay), o el desarrollo de la personalidad en todas sus dimensiones (Paraguay) o potencialidades (Perú), abarcando una variedad de aspectos que dan cuenta de las numerosas expectativas depositadas en la educación. Por ejemplo, Perú plantea como fin formar personas capaces de lograr 
su realización "ética, intelectual, artística, cultural, afectiva, física, espiritual y religiosa"; Chile, "el desarrollo espiritual, ético, moral, afectivo, intelectual y físico". Uruguay - con una fuerte tradición laica - excluye el componente religioso, afirmando como fin de la educación "el pleno desarrollo físico, psíquico, ético, intelectual y social de todas las personas sin discriminación alguna". Esta multiplicidad de dimensiones se vincula con la idea de educación permanente, una noción que comienza a tomar fuerza entre los años 60 y 70, en el contexto desarrollista, adquiere nuevos ribetes con el neoliberalismo y hoy aparece incluida en las leyes vigentes.

Resulta significativo observar los sentidos atribuidos a los fines de la educación. En varios casos, son asociados con la identidad nacional y sus valores (Argentina, Bolivia, Uruguay, Venezuela), la comunidad nacional (Perú) o la cultura nacional (Colombia y Paraguay), desarrollando definiciones que entran en una compleja relación con el respeto a los particularismos y la diversidad cultural, como veremos más adelante. Asimismo, la mayoría incorporan como fin la consolidación de la democracia o la formación para vivir en democracia (Argentina, Chile, Paraguay, Perú, Uruguay).

Otro aspecto que comparten estas leyes respecto de la orientación de la educación es la afinidad que establecen entre la preparación para el ejercicio de la ciudadanía, la vigencia de los derechos humanos y la promoción de la paz, serie que, en algunos casos, se completa con el valor de la solidaridad y/o la tolerancia (Argentina, Brasil, Colombia, Chile, Perú, Uruguay y Venezuela).

También se establecen asociaciones entre la educación y la cultura con diferentes expresiones, que van desde la preservación del patrimonio o la herencia cultural (Argentina y Paraguay) hasta la creación de cultura (Perú), la comunicación creativa de la cultura de la comunidad (Paraguay) y el respeto a la diversidad cultural (Argentina, Colombia, Chile, Paraguay, Perú).

Venezuela y Bolivia van más allá. Venezuela establece que la educación es "pluricultural, multiétnica, intercultural, y plurilingüe". Bolivia, en sintonía con su nueva Constitución, que en un giro inédito e histórico establece el Estado plurinacional, asigna a la educación un lugar primordial disponiendo que estará "orientada a la reafirmación cultural de las naciones y pueblos indígenas originarios campesinos, las comunidades interculturales y afrobolivianas en la construcción del Estado plurinacional y el vivir bien".

Estos países incorporan, junto al reconocimiento de la pluralidad de culturas, la idea de transformación cultural y social a través de las nociones de emancipación e integración caribeña (Venezuela) y de descolonización (Bolivia). La ley venezolana afirma que la educación se orienta a promover la creación, transmisión y reproducción de las manifestaciones culturales para apreciar y transformar la realidad, y que debe formar "para la participación activa, consciente y solidaria en los procesos de 
transformación individual y social, consustanciada con los valores de la identidad nacional, con una visión latinoamericana, caribeña, indígena, afrodescendiente y universal".

Por su parte, la legislación boliviana afirma que debe ser "descolonizadora, liberadora, revolucionaria, anti-imperialista, despatriarcalizadora y transformadora de las estructuras económicas y sociales". Estas nociones estructuran la ley boliviana y constituyen una diferencia sustancial respecto de las otras leyes de la región. Sólo la venezolana tiene cierta afinidad, estableciendo, como principios de la educación, la democracia participativa, la igualdad entre todos los ciudadanos y ciudadanas sin discriminaciones de ninguna índole, la formación para la independencia, la libertad y la emancipación, entre otros.

\section{Sobre el rol del Estado: entre la subsidiariedad y la principalidad}

Los Estados nacionales han tenido un rol central en la configuración, institucionalización y expansión de los sistemas educativos, asumiendo un rol principal en su regulación y desarrollo (Tenti Fanfani, 2006), de modo que un análisis de las leyes vigentes no puede prescindir de estudiar qué rol atribuyen al Estado.

La mayoría de las leyes sancionadas en la última década, en un contexto de revisión y crítica de los gobiernos neoliberales de décadas anteriores, contienen afirmaciones que dan cuenta de la principalidad del Estado respecto de la responsabilidad por la educación. En los casos de Argentina y Uruguay, el Estado asume un rol principal en la responsabilidad por garantizar una educación integral, permanente y de calidad para todos los habitantes a través del financiamiento y de la definición y el desarrollo de la política educativa. Perú establece que el Estado debe "ejercer un rol normativo, promotor, compensador, concertador, articulador, garante, planificador, regulador y financiador de la educación nacional". Sin embargo, estas afirmaciones se mixturan con otras que lo aproximan a un rol subsidiario, como las que establecen que el Estado debe "valorar el aporte de las instituciones privadas que brindan servicios educativos de calidad" (volveremos sobre esto más adelante).

Las leyes de Bolivia y Venezuela son especialmente enfáticas respecto de la responsabilidad estatal. Bolivia estipula que la educación constituye una función suprema y primera responsabilidad financiera del Estado, que tiene la obligación indeclinable de sostenerla, garantizarla y gestionarla. Asimismo, establece que el Estado y la sociedad tienen responsabilidad plena sobre el sistema educativo. En el caso venezolano, el Estado es reconocido como "Estado docente": "el Estado docente es la expresión rectora del Estado en Educación, en cumplimiento de su función indeclinable y de máximo interés como derecho humano universal y deber social fundamental, inalienable, irrenunciable, y como servicio público que se materializa en las políticas 
educativas". En ambos casos, el énfasis en el papel principal del Estado está en estrecha relación con el carácter social del derecho a la educación que establecen.

Esta principalidad estatal en los países mencionados contrasta con las orientaciones hacia la subsidiariedad del Estado que caracterizaron las leyes sancionadas en los ‘90. De acuerdo con López (2007), la actual revisión de la estructura normativa de la educación se funda en un tiempo histórico distinto, en el que varios países han expresado la voluntad de dejar atrás las políticas que signaron el período de hegemonía neoliberal. En las leyes, pero especialmente en los documentos preliminares, se manifiesta explícitamente esta intención. Quizás la excepción resulte Chile, cuya ley, a pesar de ser reciente, replica enunciados propios de los '90, en los cuales la responsabilidad estatal tiene menos alcance y asume un rol subsidiario al definir las funciones del Estado en torno a la protección de los derechos y deberes de los padres de educar a sus hijos.

Las leyes sancionadas en los ' 90 presentan diferencias. La ley de Paraguay establece que el Estado garantizará el derecho de aprender, la igualdad de oportunidades y la libertad de enseñar, como así también el derecho a la educación religiosa, asumiendo, de este modo, un rol subsidiario, reducido a proveer garantías para el cumplimiento de un derecho de los particulares. La ley colombiana también define un Estado subsidiario, que debe disponer recursos y acciones para que la familia, como núcleo fundamental y primer responsable de la educación de los hijos, vea realizado su derecho a la educación. Para ello, establece mecanismos de subsidio a la demanda otorgados por el Estado a las familias de menores ingresos económicos para el pago de establecimientos educativos estatales o privados.

La "Lei de Diretrizes e Bases" (LDB) de Brasil establece que la educación es un deber de la familia y del Estado, a la vez que coloca al Estado en un lugar principal en términos de responsabilidad por el acceso a la educación, disponiendo que debe garantizar la enseñanza fundamental obligatoria y gratuita, la universalización de la enseñanza media gratuita, la atención a alumnos con necesidades educativas especiales, la atención de los niños/as de cero a seis años de edad, el acceso a niveles superiores de educación, entre otros aspectos. Se observan así superposiciones de concepciones diferentes que se vinculan con el hecho de que, si bien esta ley fue sancionada en los ‘90, es la resultante del Foro Nacional de Educación Pública y un movimiento amplio e intenso de participación y debate impulsado con la vuelta a la democracia (Oliveira, 2007).

\section{Lo público, lo privado y las relaciones entre el Estado y la Iglesia Católica}

Los procesos de conformación de los Estados nacionales en Occidente fueron, en buena medida, procesos de disputa con la Iglesia. En Latinoamérica, la tensión 
en torno a la secularización de los Estados fue intrínseca a la configuración de los sistemas educativos de la región, ya que la disputa respecto de quién debía asumir la función de educar en los estados oligárquicos nacientes constituyó uno de los elementos centrales de la rivalidad entre la Iglesia Católica y el Estado (Ossenbach, 1993; Puiggrós, 2003; Paviglianiti, 1993). Esta tensión, resuelta de maneras dispares en los diferentes países, se reedita en diversos momentos históricos y aún tiene vigencia, como pudo observarse recientemente en en Ecuador. El proyecto de ley que había aprobado la Asamblea Nacional de Ecuador, en enero de 2011, establecía entre los principios generales el laicismo y la garantía de una educación pública laica, respetando y manteniendo la independencia frente a las religiones, cultos y doctrinas. Sin embargo, el proyecto recibió numerosos vetos por parte de la presidencia, uno de los cuales disponía la enseñanza de religión en los establecimientos laicos. Esta modificatoria finalmente no fue aprobada, pero generó un gran debate. ${ }^{2}$

Las leyes de educación vigentes en América del Sur evidencian que esta tensión aún no está saldada. De todas las leyes consultadas, sólo tres declaran que la educación es laica (Bolivia, Uruguay y Venezuela) y una contiene una débil mención ${ }^{3}$ (Chile). Otros tres países no refieren al tema (Argentina, Paraguay y Perú) y dos (Brasil y Colombia) establecen la educación religiosa como parte de la formación básica en las instituciones dependientes del Estado, de asistencia opcional.

Por otro lado, la presencia de la Iglesia es significativa en varias de las leyes. Se evidencia en artículos que reconocen algunas cuestiones largamente reclamadas por esta institución, como lo son la libertad de enseñar y el derecho a la educación religiosa. Un ejemplo es la ley de Paraguay, que si bien no habilita la educación religiosa en las escuelas oficiales, sí sostiene que el Estado "garantizará igualmente la libertad de enseñar, sin más requisitos que la idoneidad y la integridad ética, el derecho a la educación religiosa y al pluralismo ideológico". Garantizar la libertad de enseñar sin mediar certificación respecto de la formación pedagógica y sin más requisito que la idoneidad e integridad ética es un guiño cuyo destinatario es la Iglesia.

Esta tensión está vinculada también con las definiciones que se incorporan en relación con lo público y lo privado en materia educativa. Históricamente, el principal agente educador privado era la Iglesia. En las últimas décadas, la educación privada creció de la mano de otros agentes cuyas demandas, así como las de sectores neoliberales pro-mercado, se articularon con las de la Iglesia y otros sectores conservadores que históricamente habían sostenido la disputa por el reconocimiento de dos principios: libertad de enseñanza - supone que el Estado debe asumir un rol subsidiario y sólo debe promover la educación ayudando a la iniciativa de los particulares - y justicia distributiva - sostiene que el Estado debe distribuir los recursos destinados a educación entre los diversos agentes a través de subvenciones 
económicas a las obras educativas (Paviglianiti, 1993; Pontífice Pio XI, 1950; Comisión Episcopal de Educación Católica, 2007). El primero aparece en el conjunto de las leyes; el segundo, en varias.

La educación privada tiene una presencia significativa en todas las leyes actualmente vigentes, tanto conformando un apartado o capítulo específico como recorriendo el conjunto de la norma. No obstante, todas también establecen que queda bajo regulación y control del Estado.

Resulta significativo que, excepto Brasil y Uruguay, no se diferencia entre educación pública y educación privada. Las normas refieren a la educación pública abarcando al conjunto del sistema y establecen tipos institucionales: establecimientos oficiales, fiscales, de gestión estatal, etc., por un lado, y establecimientos particulares o de gestión privada, por otro. En algunos casos se amplía la tipología, como es el caso de Argentina, que distingue entre instituciones educativas de gestión privada, de gestión cooperativa y de gestión social; y de Bolivia, que refiere a unidades educativas fiscales, privadas y de convenio (con fines de servicio social y sin fines de lucro, bajo entidades religiosas). Chile distingue, dentro de la educación particular, a las "escuelas subvencionadas" y las "escuelas pagadas". Perú identifica instituciones "públicas de gestión directa por autoridades educativas", "públicas de gestión privada, por convenio con entidades sin fines de lucro que prestan servicios educativos gratuitos" y "de gestión privada".

En algunas leyes, la educación particular adquiere una mayor gravitación. Chile desarrolla una ingeniería legal compleja en la que no distingue entre la educación particular y la estatal, al disponer que cuentan con reconocimiento oficial los establecimientos que tienen un sostenedor ${ }^{4}$ y se ajustan a una serie de características y requisitos, y que son sostenedores "las personas jurídicas de derecho público, tales como municipalidades y otras entidades creadas por ley, y las personas jurídicas de derecho privado". La ley peruana exalta la educación privada, sosteniendo que "contribuye a la ampliación de la cobertura, a la innovación, a la calidad y al financiamiento" y que es función del Estado "valorar el aporte de las instituciones privadas que brindan servicios educativos de calidad". Argentina establece que los agentes de la educación privada tienen los siguientes "derechos: crear, administrar y sostener establecimientos educativos; matricular, evaluar y emitir certificados y títulos con validez nacional; nombrar y promover a su personal directivo, docente, administrativo y auxiliar; formular planes y programas de estudio; aprobar el proyecto educativo institucional de acuerdo con su ideario y participar del planeamiento educativo". En el caso de Colombia, la educación privada aparece referida de manera continua en todos los artículos de la ley y dispone una serie de elementos que dan cuenta de su centralidad, como establecer que el Estado dará "subsidios y créditos a la demanda educativa" para las familias de menores ingresos destinados 
al pago de matrícula y otros gastos en establecimientos estatales o privados y que se otorgarán subsidios a las instituciones privadas, aclarando que "el subsidio no implica la pérdida de autonomía de la institución".

\section{Las concepciones en torno al derecho a la educación}

Las concepciones de la educación como derecho constituyen una dimensión relevante para el análisis propuesto, ya que dan fundamento a las definiciones en torno a los fines de la educación, el rol del Estado y de otros actores, así como la orientación general, en materia de política educativa, para aproximarse a la realización de este derecho. En las leyes, las definiciones del derecho a la educación son variables y con diversas traducciones a la hora de plantear estrategias para consolidar su vigencia. En algunos casos, el derecho a la educación aparece como derecho de todas las personas (Chile y Colombia) o derecho de cada habitante (Paraguay), desde una concepción individualista, que suele ir de la mano con el rol subsidiario del Estado como mero protector del derecho individual de las personas.

En las leyes educativas más recientes, algunos países han recuperado la dimensión social del derecho a la educación que se expresa en su definición como derecho fundamental, como sucede con Bolivia y Perú, como un derecho humano fundamental y un bien público y social (Uruguay), o como un derecho humano universal y un deber social fundamental, inalienable e irrenunciable (Venezuela). Argentina, en una formulación híbrida, plantea que la educación es un derecho personal y social, y un bien público. Esta recomposición del derecho a la educación luego de los ‘ 90 constituye una de las columnas sobre la que se sostiene el reposicionamiento del Estado asumiendo una función promotora.

El modo en que las leyes incorporan el valor de la igualdad constituye una dimensión central del derecho a la educación, que cristaliza sus alcances. Luego de su dilución en el último tercio del siglo xx, la noción de igualdad aparece en las nuevas leyes con diversas expresiones. En Bolivia, Brasil y Venezuela, como principio general de la educación y como fin de las acciones. En Chile, Perú, Uruguay y Paraguay es referida en términos de igualdad de oportunidades y de equidad. Argentina, en una posición intermedia, utiliza una u otra formulación en diversos artículos.

Esta "vuelta" a la igualdad - sea pensada en términos de igualdad educativa o de igualdad de oportunidades - viene acompañada de componentes novedosos en relación con las normativas anteriores, que se inscriben en debates recientes. Uno de ellos es el del universalismo, al que hacen referencia todas las leyes aprobadas en el nuevo siglo, aunque de manera muy dispar. Varias refieren al imperativo y/o el propósito de universalizar el acceso y la permanencia en la educación básica (Argentina, Perú, Uruguay), los conocimientos y la sabiduría (Bolivia) o el derecho 
a la educación (Venezuela). Chile sostiene la universalidad como principio de la educación sin explicitar más. Argentina refiere también a garantizar la inclusión a través de políticas universales. Otro componente es el énfasis en el acceso y en la permanencia, luego de que se instalara la insuficiencia de la inclusión cuando ésta es asociada exclusivamente con la garantía del acceso.

En sintonía con lo anterior, varias leyes proponen distintas perspectivas para hacer frente a las diversas formas de injusticia y discriminación, estableciendo que los Estados deben desarrollar estrategias para garantizar condiciones materiales para la realización del derecho a la educación (Argentina, Bolivia, Brasil, Uruguay), programas sociales específicos (Bolivia) o políticas compensatorias (Perú).

Colombia constituye un caso peculiar. Su ley no hace mención ni a la equidad, ni a la igualdad, y sólo refiere a la universalidad para fundamentar el aliento a formatos acuñados por la Nueva Derecha, contemplando, con el fin de asegurar la universalidad de la educación básica, la conformación de asociaciones de padres y educadores para crear establecimientos educativos que se financien con los aportes de los padres y ayuda del Estado.

Un aspecto nodal en el que las leyes hacen hincapié para consolidar la realización del derecho a la educación es, como hemos visto, el del respeto a la diversidad cultural y el reconocimiento de las culturas de pueblos originarios y de minorías étnicas y de género. Todas las leyes hacen referencias a la no discriminación, en algunos casos, con ciertos énfasis, como Uruguay, que refiere a la transformación de los estereotipos discriminatorios por motivos de edad, género, raza, etnia u orientación sexual.

Con excepción de Paraguay y Uruguay, todas las demás leyes establecen la educación intercultural bilingüe o plurilingüe, pero con diferencias significativas. Perú garantiza el derecho de los pueblos indígenas a una educación en condiciones de igualdad, establece que la Educación Bilingüe Intercultural se ofrece en todo el sistema educativo y asegura la participación de miembros de pueblos indígenas en la formulación y ejecución de los programas. Chile, por el contrario, establece que si las instituciones educativas contaran con un alto porcentaje de alumnos indígenas, se procurará que ellos desarrollen aprendizajes que les permitan mantener el dominio de la lengua indígena y el conocimiento de la historia y cultura de su pueblo. En Paraguay, sólo se afirma que la educación de los grupos étnicos tendrá como finalidad su integración a la sociedad paraguaya, respetando sus valores culturales.

En el marco de un abordaje de la cuestión considerablemente diferente, Venezuela y Bolivia otorgan un lugar importante a la igualdad de género y el carácter pluricultural, plurilingüe y multiétnico de una educación igualitaria, equitativa e inclusiva. En la ley boliviana, la educación intercultural plurilingüe resulta transversal 
a todos los contenidos de la ley. Afirma la necesidad de enriquecimiento intercultural e intracultural dentro del Estado Plurinacional y de considerar la diversidad de cosmovisiones y culturas. En el caso de Venezuela, se establece la necesidad de afianzar los saberes populares y ancestrales de los pueblos latinoamericanos, caribeños, indígenas y afrodescendientes, otorgándoles un lugar central.

Por último, dos cuestiones centrales, vinculadas con el alcance del derecho a la educación y sus formas de realización, son la gratuidad y la obligatoriedad. Todas las leyes, excepto Colombia, establecen la gratuidad en las instituciones dependientes del Estado. Argentina, Bolivia, Brasil, Chile, Perú, Uruguay y Venezuela disponen la gratuidad en todos los niveles, mientras que Paraguay no incluye el nivel medio.

En cuanto a la obligatoriedad, Argentina, Bolivia, Perú y Uruguay estipulan que la obligatoriedad se extiende desde el nivel inicial o algunos años de ese nivel, hasta la educación secundaria, abarcando así entre 13 y 14 años de escolaridad obligatoria. En el caso de Brasil, la ley establece que es obligatoria la enseñanza fundamental, de 9 años, y que debe universalizarse la enseñanza media. No obstante, a través de una enmienda constitucional de 2009, se han legislado 14 años de escolaridad obligatoria y gratuita para la educación inicial, fundamental y media. Chile dispone 12 años de educación obligatoria que abarcan primaria y secundaria. Colombia, 10 años de obligatoriedad compuestos por preescolar, primaria y secundaria básica. Por su parte, Paraguay también legisla 10 años, pero no incluye la educación media.

La tendencia general en la región ha sido a un aumento sustantivo de la obligatoriedad y la gratuidad, tanto en cantidad de años como en los ciclos que comprende.

\section{Continuidades y transformaciones: nuevas y viejas orientaciones en la educación suramericana}

Las leyes sancionadas en el nuevo siglo contienen elementos de ruptura y cambio respecto de las leyes precedentes, pero de signos diversos. Una de las dimensiones en la que es posible identificar cambios sustantivos es aquella vinculada con el rol que asume el Estado respecto de la garantía y la responsabilidad por la educación, lo que se vincula, a su vez, con las extensiones de la obligatoriedad y de la gratuidad, como hemos visto.

En este sentido, se observan intentos de redefinir el derecho a la educación en términos de un derecho social en asociación con la introducción de compromisos en torno a la igualdad y la universalidad, lo que implica un cambio significativo en el discurso y en la racionalidad política desde la cual se piensa lo social. No obstante, 
al mismo tiempo se sostienen con fuerza formulaciones propias de una concepción de la educación como derecho individual, que se superponen o mixturan con las anteriores.

La presencia que adquiere la integración en la diversidad cultural constituye otro cambio significativo. Casi todas las leyes establecen la educación intercultural bilingüe o plurilingüe y, en varias de ellas, esta adquiere una centralidad impensada pocos años atrás.

Sin embargo, las leyes sancionadas a partir del 2000 también contienen algunas continuidades respecto de las políticas educativas de los 90, mostrando cómo se filtran concepciones, contenidos y propuestas propios del neoliberalismo

Una continuidad significativa se vincula con el lugar que tiene la educación privada en sus articulados. Como es sabido, en las últimas décadas del siglo xx, la educación privada se expandió bajo el imperativo del mercado desde una lógica neoliberal. La confluencia de neoconservadores y neoliberales en el interés por la educación privada, en el marco de gobiernos afines, dio un gran impulso al sector que se tradujo en el reconocimiento, en las leyes de los 90, de ciertas condiciones reclamadas (como la autonomía pedagógica, los subsidios, la emisión de certificados, la elección de los docentes según reglas propias, la definición de planes y programas, entre otras). ${ }^{5}$ La educación privada ingresa, en varias de las leyes de educación de aquella época, de un modo que la puso en pie de igualdad con la educación pública (Paviglianiti, 1995).

En las nuevas leyes, esta situación, en general, se mantiene. Por un lado, en varias de ellas (Argentina, Bolivia, Chile, Perú, Venezuela) se habla de la educación pública para referir al conjunto del sistema, e inscribiendo dentro de la educación pública tanto los establecimientos estatales como las instituciones particulares. Sólo Brasil y Uruguay marcan una distinción clara entre educación pública y privada.

En segundo lugar, las numerosas referencias a la idea de "calidad educativa" denotan cómo ciertos marcos de pensamiento neoliberales siguen funcionando. La idea de calidad en relación con la educación nació al calor de las reformas neoliberales. Las leyes de los 90 planteaban el "mejoramiento de la calidad" como uno de los objetivos centrales de la política educativa, asociándola a la evaluación de rendimientos, la eficacia y la eficiencia del sistema (Souza y Oliveira, 2003).

En las leyes educativas recientes, la idea de calidad tiene una presencia fuerte pero presenta matices. En el caso de Perú, las definiciones relativas a la calidad se identifican plenamente con las de los 90, asociando calidad educativa con rendición de cuentas a "los usuarios" y a la población, y con una formación "flexible" que permita enfrentar los retos del desarrollo. 
En Argentina y Uruguay, es referida como parte de las responsabilidades que el Estado debe asumir en cuanto a la educación (proveer una educación de calidad), de modo similar a lo que sucedía en el marco de las reformas neoliberales. La calidad cualifica el derecho a la educación que garantiza el Estado y los aprendizajes "de calidad" (y con "igualdad de oportunidades") se tornan el objetivo central de la política educativa. Lo que resulta relevante, en el caso de ambos países, es cómo la permanencia de la calidad se anuda con la reposición de un lugar más principal para el Estado nacional y de una dimensión más social para el derecho a la educación, al que se incorporan valores como el de la igualdad.

Esta persistencia de la noción de calidad, sin embargo, no está exenta de que sea el lugar de llegada de otras significaciones. En el caso de la ley de Bolivia, la garantía de la calidad educativa aparece asociada a la defensa de la soberanía, la identidad plurinacional y la diversidad sociocultural. Aún más, la ley introduce un elemento novedoso al establecer la implementación de estrategias de seguimiento y evaluación con participación social, a la vez que asume posición en relación con los procesos de internacionalización, al disponer, "en el marco de la soberanía e identidad plurinacional, plantear a nivel internacional indicadores, parámetros de evaluación y acreditación de la calidad educativa que respondan a la diversidad sociocultural y lingüística del país".

En la ley venezolana, la idea de educación de calidad aparece junto al carácter público, social, gratuito, laico, igualitario, crítico, multiétnico, intercultural y plurilingüe de la misma.

Estas continuidades y distanciamientos, con todos sus matices, permiten dimensionar cómo conviven conceptos de racionalidades políticas divergentes, propios de una crisis hegemónica, en los que elementos propios de la construcción hegemónica previa se mixturan y redefinen en la configuración de nuevos discursos y en la construcción de instrumentos legales que abonen a proyectos sociopolíticos alternativos.

\section{Continuidades, rupturas y transiciones: entre el neoliberalismo y el postconsenso de Washington}

A lo largo de este artículo hemos desarrollado un análisis comparativo de las leyes actualmente vigentes en los países latinoamericanos de América del Sur. Para ello, nos hemos detenido especialmente en los fines que establecen para la educación, el rol que asignan al Estado y a otros actores, y el modo en que es definido el derecho a la educación.

La primera década del siglo xxi ha sido particularmente productiva en términos de leyes generales de educación que revisan aspectos importantes de sus 
antecesoras sancionadas en los '90. El análisis desarrollado evidenció el modo en que el contexto de crisis del Consenso de Washington habilitó otras enunciaciones político-educativas que hubieran sido casi impensables dos décadas atrás. En particular, el reposicionamiento de los Estados, asumiendo un rol principal en educación, parece haber sido una de las consecuencias más visibles. Esta consecuencia no es meramente retórica, sino que implica un conjunto de asunciones respecto de la responsabilidad del Estado en torno de lo social introducidas en la agenda políticopedagógica por parte de una serie de actores y fuerzas sociales que, en este nuevo contexto, alcanzaron lugares de visibilidad en la arena política, sindical y educativa de los países de la región.

Si el Consenso de Washington suponía pensar las políticas sociales a partir de los mandatos de desregulación, subsidiariedad del Estado, primacía del mercado, centralidad de los particulares y políticas focalizadas, claramente lo que aparece con más fuerza en varias de las nuevas leyes supone la crisis de ese consenso: principalidad y regulación del Estado, garantía de derechos, igualdad y universalización (o al menos ampliación) de las políticas. Es en este sentido que hablamos del postconsenso de Washington.

Para el análisis de estas nuevas enunciaciones en el contexto del postconsenso de Washington ha sido fundamental realizar dos operaciones analíticas. La primera de ellas ha sido la de considerar - dentro de las posibilidades de este artículo - el papel de la historia en términos del modo en que las diversas matrices socioeducativas prefiguran las discusiones y definiciones sobre los temas político-pedagógicos que son parte de la agenda. Sin una mirada a la construcción histórica de la educación institucionalizada en la región, difícilmente hubiera sido posible analizar, por ejemplo, por qué la cuestión de la laicidad encuentra diversos posicionamientos y variadas resoluciones en los países suramericanos.

La segunda operación analítica ha sido la de procurar identificar continuidades y rupturas con el pasado reciente. Esta opción ha resultado fértil no sólo en términos de identificar las cuestiones que permanecen y las que han cambiado, sino también porque nos ha permitido dar cuenta de la complejidad de los procesos de cambio político-educativo y del modo en que ellos suponen sedimentaciones y articulaciones de sentidos que no responden a una voz unívoca sino a discursos heterogéneos que se mixturan, en algunos casos de modo inédito. Ello posibilita considerar que en las definiciones legales convivan definiciones conservadoras del derecho a la educación como derecho personal con enunciaciones fundadas en la educación como derecho social, articuladas con definiciones de principalidad estatal, o que la calidad de la educación sea asociada a mecanismos de accountability, en algunos casos, y, en otros, a la definición del carácter social, crítico, creativo, intercultural, multiétnico y plurilingüe de la educación. 
Por lo aquí señalado, no es posible sostener que las leyes del pasado son "neoliberales" y las más recientes algo totalmente distinto, aún cuando resulta claro que Bolivia y Venezuela se distinguen de todas las demás. A la hora de mirar la región en su conjunto, es preciso pensar la trama abierta entre el neoliberalismo y el postconsenso de Washington como un lugar de disputa por los sentidos de la educación, de negociaciones de significado y de lucha cultural por definir las orientaciones políticoeducativas, las nociones de igualdad que las sustentan, la concepción de derecho a la educación en que deben fundarse y el rol que los Estados deben asumir en este proceso. Esta lucha, que es disputa por la hegemonía, se mantiene vigente para la región. De esto dan cuenta la gran cantidad de matices que es posible identificar en un análisis comparado y, también, el modo en que significados neoliberales se conjugan con otras definiciones, incluso en aquellos países comprometidos, con mayor o menor radicalidad, en construcciones que se proponen como críticas y alternativas respecto del neoliberalismo. Ello también nos advierte respecto del peso que aún tiene el neoliberalismo en el modo en que se construyen los discursos políticos-pedagógicos y en los límites que todavía traza respecto de lo que es posible de ser dicho y pensado en torno a la educación. Dar cuenta de esos límites y de la vigencia de algunas premisas neoliberales constituye, entonces, una tarea central para el análisis político-educativo y se torna un paso fundamental en el propósito de continuar abriendo horizontes más democráticos e igualitarios para la educación en y desde el Sur.

\section{Notas}

1. El relevamiento de las leyes fue realizado con la colaboración de la lic. Laura Finvarb (UBA, Argentina).

2. Ver, entre otros, "La Asamblea rechazó la materia de religión en planteles laicos”, El Comercio, Quito, 16 feb. 2011.

3. Esta ley refiere a una educación "fundada en un proyecto educativo público, laico, esto es, respetuoso de toda expresión religiosa".

4. El término sostenedor identifica una figura jurídica que representa a quien asume la responsabilidad por la institución.

5. En algunos casos, estas condiciones ya habían sido reconocidas, pero en instrumentos legales de menor jerarquía que una ley general de educación.

\section{Referencias}

COMISIÓN EPISCOPAL DE EDUCACIÓN CATÓLICA. La Iglesia y la nueva Ley de Educación Nacional. Buenos Aires: Conferencia Episcopal Argentina, 2007.

FELDFEBER, M. La propuesta educativa neoliberal. Revista Espacios, Buenos Aires, n. 22, p. 50-58, 1997. 
FELDFEBER, M. Una transformación sin consenso: apuntes sobre la política educativa del gobierno de Menem. Versiones, Buenos Aires, n. 11, p. 8-20, 2000.

FELDFEBER, M.; ANDRADE OLIVEIRA, D. (Comp.). Políticas educativas y trabajo docente. Nuevas regulaciones. ¿Nuevos sujetos? Buenos Aires: Novedades Educativas, 2006.

GENTILI, P. Marchas y contramarchas: el derecho a la educación y las dinámicas de exclusión incluyente en América Latina. Revista Iberoamericana de Educación, Madrid, n. 49, p.19-57, 2009.

KRAWCZYK, N.; VIEIRA, V.L. A reforma educacional na América Latina nos años 1990. Uma perspectiva históricosociológica. São Paulo: Xamã, 2008.

LÓPEZ, N. Las nuevas leyes de educación en América Latina. Una lectura a la luz del panorama social y educativo de la región. Campaña Latinoamericana por el Derecho a la Educación. Buenos Aires: IIPE-UnESCO, 2007.

OLIVEIRA, D.A. A educação básica na Lei de Diretrizes e Bases da Educação Nacional: breve balanço sobre a organização escolar e o trabalho docente. In: SouzA, J.V.A. Formação de professores para a educação básica. Dez anos da LDB. Belo Horizonte: Autêntica, 2007.

OLIVEIRA, R.P. Reformas educativas no Brasil na década de 90. In: CATANI, A.M.; Oliveira, R.P. Reformas educacionais em Portugal e no Brasil. Belo Horizonte: Autêntica, 2000. p. 77-94.

OSSENBACH SAUTER, G. Estado y educación en América Latina a partir de su independencia (siglos XIx y xx). Revista Iberoamericana de Educación, Madrid, n. 1, 1993. Disponible en: <http://www.rieoei.org/oeivirt/rie01.htm>. Acceso em: 31 jul. 2005.

PAVIGLIANITI, N. El derecho a la educación: una construcción histórica polémica. Buenos Aires: opfyL-uba, 1993. (Serie Fichas de Cátedra).

PAVIGLIANITI, N. La Ley Federal de Educación como elemento de regulación de la realidad educacional argentina. Buenos Aires: Facultad de Ciencias Humanas, Universidad Nacional de la Plata, 1995. (Serie Pedagógica n. 2).

PONTÍFICE PÍO XI. Divini illius magistri. In: Colección de Encíclicas Pontificias, 18301950. Madrid: Guadalupe, 1950, p. 650-680.

PUIGGRÓS, A. Qué pasó en la educación argentina: breve historia desde la conquista hasta el presente. Buenos Aires: Galerna, 2003.

SOUZA, S.Z.L.; OLIVEIRA, R.P. Políticas de avaliação da educação e quase mercado no Brasil. Educação \& Sociedade, Campinas, v. 24, n. 84, p. 873-895, 2003. 
Las leyes de educación en los comienzos del siglo XXI...

TENTI FANFANI, E. (Comp.). El oficio de docente. Vocación, trabajo y profesión en el siglo xxi. Buenos Aires: Siglo xxI, 2006.

TIRAMONTI, G. Modernización educativa de los '90. ¿El fin de la ilusión emancipatoria? Buenos Aires: flacso; Temas Grupo Editorial, 2001.

Recebido em março de 2011.

Aprovado em maio de 2011. 